\title{
(C) OPEN ACCESS \\ Assessing the impact of a Carer Support Needs Assessment Tool (CSNAT) intervention in palliative home care: a stepped wedge cluster trial
}

\author{
Gunn Eli Grande, ${ }^{1}$ Lynn Austin, ${ }^{1}$ Gail Ewing, ${ }^{2}$ Neil O'Leary, ${ }^{3}$ \\ Chris Roberts ${ }^{3}$
}

${ }^{1}$ School of Nursing, Midwifery and Social Work, University of Manchester, Manchester, UK ${ }^{2}$ Centre for Family Research, University of Cambridge, Cambridge, UK

${ }^{3}$ Centre for Biostatistics, Institute of Population Health, University of Manchester, Manchester, UK

\section{Correspondence to}

Prof Gunn Eli Grande, Jean McFarlane Building, Oxford Road, Manchester M13 9PL, UK Gunn.grande@manchester.ac.uk

Received 27 February 2015 Revised 2 September 2015 Accepted 25 November 2015 Published Online First 30 December 2015

\section{CrossMark}

To cite: Grande $\mathrm{GE}$,

Austin L, Ewing G, et al. BMJ

Supportive \& Palliative Care

2017:7:326-334.

\section{ABSTRACT}

Objectives To test the impact on family carers of a Carer Support Needs Assessment Tool (CSNAT) intervention to facilitate carer-led assessment and support during end of life care. Method Mixed method, part-randomised, stepped wedge cluster trial with 6 palliative home care services comparing carers receiving the intervention with those receiving standard care. Postal survey with carers $4-5$ months postbereavement measured adequacy of end of life support, current mental and physical health (Short Form 12 Health Survey SF-12), level of grief (Texas Revised Inventory of Grief, TRIG) and distress (Distress Thermometer, DT), place of death and carer satisfaction with place of death. Results Surveys were sent to 3260 (76\%) carers of 4311 deceased patients; 681 (21\%) were returned ( $\mathrm{N}=333$ control, $\mathrm{N}=348$ intervention). Compared with controls, intervention carers had significantly lower levels of early grief, better psychological and physical health, were more likely to feel the place of death was right, and patients were more likely to die at home. However, differences were small and process measures showed low level of implementation, indicating differences may partially relate to increased awareness of carer issues rather than a direct impact of the intervention.

Conclusions Carers had better outcomes in the intervention condition, albeit modest. If this can be achieved through low level implementation and awareness raising of carers' needs from implementation activities, substantial impact should be possible if the CSNAT intervention can be fully implemented with a majority of carers. The study illustrates challenges of implementing and testing a complex intervention in real-life practice and of achieving comprehensive carer assessment and support in line with government recommendations.

\section{INTRODUCTION}

Family carers are central to enabling patients to remain at home at end of life. ${ }^{1}{ }^{2}$ However, carers may suffer worse physical and psychological well-being prebereavement and postbereavement from care giving. ${ }^{3}{ }^{4}$ Better support for carers may promote better bereavement outcomes, ${ }^{5-7}$ improved quality of care for patients ${ }^{8}$ and plausibly, increase likelihood of death at home. To ensure that carers' support needs are assessed and addressed $^{9} 10$ we developed a Carer Support Needs Assessment Tool (CSNAT) in collaboration with the National Association for Hospice at Home to provide an evidence-based carer assessment tool suitable for practice. ${ }^{11}$

The CSNAT consists of 14 items representing broad domains with which carers require support during care giving at end of life. These include support to help carers support the patient, for example, with knowing what to expect, who to contact, how to manage symptoms and medicines; and support for carers themselves, for example, with feelings and worries, daytime or night time respite. The CSNAT enables carers to identify and prioritise domains where they need more support and then determine, in discussion with a practitioner, what they would find helpful to address needs. This constitutes the CSNAT intervention, a process facilitated by practitioners, but led by carers. Desired support may 
include help practitioners can provide immediately (eg, reassurance, advice, information), help to involve other family members, signposting towards external support or referral for further input. The CSNAT domains were developed from focus groups and interviews with 75 bereaved carers ${ }^{11}$ and their face and criterion validity tested with 225 current carers. ${ }^{12}$ Piloting and feasibility work with practitioners showed perceived benefits of the CSNAT intervention and also some challenges of implementation that informed further CSNAT training and support. ${ }^{13} 14$

While promising, the CSNAT intervention required further testing to establish whether it improved carer outcomes. However, high demand for an evidencebased carer assessment tool among our service partners and their belief in the benefits of the CSNAT intervention made it difficult to conduct a conventional randomised controlled trial. Randomising individuals within services to the control arm was likely to be seen as unacceptable and also entail risk of cross-contamination between intervention and control arms. Similarly, if services were assigned to a 'control cluster' they were more likely to disengage. Instead a stepped wedge trial design, a variant of the cluster trial, enabled us to build a robust evaluation around a 'controlled' release of the intervention into practice in a situation where providers were keen to start using the CSNAT, ${ }^{15}$ and to capitalise on the natural experiment this offered. ${ }^{16}$ Stepped wedge cluster designs are recommended where there is strong belief in the benefits of the intervention, its costs are low and side effects unlikely. ${ }^{17}{ }^{18}$ Further, stepped wedge designs are suited to situations where geographical and pragmatic constraints prevent simultaneous implementation across study settings, and allows all participating sites to eventually use the intervention, thus preventing the disengagement within control sites which may be a problem in conventional cluster trials. ${ }^{17} 18$

\section{METHODS}

\section{Study design}

A stepped wedge cluster part-randomised trial ${ }^{17} 18$ was used to test the impact of the CSNAT intervention on carer and patient outcomes. The clusters were six palliative home care sites (table 1). Sites started using the intervention one by one at three monthly intervals, the time before the intervention representing their control period (table 2). Site practitioners would start using the CSNAT intervention with all carers of patients on their caseload from their intervention start date. All carers of patients who died before this date would only have received the usual service input and so were part of the control condition. After the intervention start date, all carers should have had the opportunity to receive the CSNAT intervention, so carers of patients who died after this date were part of the intervention condition. This was therefore a repeated cross-section stepped wedge design with different individuals in each cluster in the preintervention and postintervention steps. ${ }^{17}$

Pragmatic constraints meant the sequence of sites beginning the intervention was not fully randomised; the sites most and least ready to fit in a practice change at study start were allocated to begin the intervention first (CSNAT intervention only) and last (control only), respectively, in the implementation sequence. The remaining sites were allocated to begin treatment in a randomised sequence in between these two (table 2). Delivery of the CSNAT intervention was recorded to monitor level of implementation, including any transition periods while the intervention was 'bedding in'.

Carer outcomes were obtained through survey of carers postbereavement, to allow assessment of longer

Table 1 Characteristics of trial services

\begin{tabular}{|c|c|c|c|}
\hline Site & Participating service & $\begin{array}{l}\text { Practitioners within teams } \\
\text { (outset of study) }\end{array}$ & $\begin{array}{l}\text { Deaths per } \\
\text { month (prestudy info) }\end{array}$ \\
\hline 1 & $\begin{array}{l}\text { Home care team, two components: } \\
\text { Specialist Palliative Care Team } \\
\text { Palliative Care Support Team }\end{array}$ & $\begin{array}{l}1 \text { Home care team manager } \\
8 \text { CNSs } \\
7 \text { RGNs } \\
6 \text { HCAs }\end{array}$ & 34 \\
\hline 2 & $\begin{array}{l}\text { Home care team, two components } \\
\text { CNS team } \\
\text { Hospice at home team }\end{array}$ & $\begin{array}{l}1 \text { CNS team manager } \\
5 \text { CNSs } \\
\text { I CNS } \\
3 \text { RGNs } \\
9 \text { HCAs }\end{array}$ & 40 \\
\hline 3 & Hospice at home service—-two teams covering different geographical areas & 18 CNSs (9 for each geographical area) & 50 \\
\hline 4 & Community Nurse Specialist Team & 26 CNSs & 100 \\
\hline 5 & Community Palliative Care Nurse Specialist Team & $\begin{array}{l}1 \text { Manager } \\
8 \text { CNSs }\end{array}$ & 25 \\
\hline 6 & Palliative Home Nursing Service & $\begin{array}{l}1 \text { Community team leader } \\
5 \text { CNSs }\end{array}$ & 30 \\
\hline
\end{tabular}

CNS, clinical nurse specialist; HCA, healthcare assistant; RGN, registered general nurse. 
Table 2 Stepped wedge trial: deaths (\% survey sent/\% survey response rate) by trial site, time interval (step) and trial arm (intervention: shaded; control: blank)

\begin{tabular}{|c|c|c|c|c|c|c|c|c|}
\hline Step & 1 & 2 & 3 & 4 & 5 & Total & Total control & Total intervention \\
\hline \multicolumn{9}{|l|}{$\overline{\text { Site }}$} \\
\hline 1 & $108(66 / 20)$ & $109(82 / 25)$ & $127(69 / 23)$ & $115(79 / 25)$ & $106(75 / 15)$ & $565(74 / 22)$ & & $565(74 / 22)$ \\
\hline 2 & $91(65 / 31)$ & $131(61 / 25)$ & $126(56 / 30)$ & $127(54 / 20)$ & $142(54 / 25)$ & $617(58 / 26)$ & $91(65 / 31)$ & $526(56 / 25)$ \\
\hline 3 & $98(74 / 29)$ & $104(77 / 30)$ & $89(74 / 30)$ & $97(85 / 28)$ & $101(80 / 21)$ & $489(78 / 27)$ & $202(76 / 29)$ & $287(80 / 26)$ \\
\hline 4 & $305(82 / 22)$ & $312(87 / 16)$ & $335(80 / 18)$ & $301(81 / 27)$ & $278(75 / 20)$ & $1531(81 / 21)$ & $952(83 / 19)$ & $579(78 / 24)$ \\
\hline 5 & $142(93 / 23)$ & $115(88 / 16)$ & $114(89 / 15)$ & $98(87 / 11)$ & $86(77 / 21)$ & $555(88 / 17)$ & $469(90 / 17)$ & $86(77 / 21)$ \\
\hline 6 & $160(82 / 12)$ & $146(67 / 13)$ & $83(72 / 15)$ & $74(41 / 13)$ & $91(60 / 18)$ & $554(67 / 14)$ & $554(67 / 14)$ & \\
\hline Total & $904(79 / 21)$ & $917(78 / 19)$ & $874(75 / 20)$ & $812(74 / 23)$ & $804(71 / 20)$ & $4311(76 / 21)$ & $2268(79 / 19)$ & $1478(72 / 24)$ \\
\hline
\end{tabular}

term impact and measurement of outcomes relative to a common 'anchor point', enabling consistent crosscomparison between carers. Earlier psychometric testing of the CSNAT $^{12}$ showed predeath outcome measures to be strongly influenced by variations in patients' stage of illness and proximity to death. Postbereavement measurement furthermore meant outcome data collection proceeded a step behind, and was managed separately from, practice delivery of the intervention, so assessment was fully blinded and intervention and data collection activities did not interfere with each other. Ethics approval was obtained from NRES Committee North WestGreater Manchester East (12/NW/0206).

\section{Implementation of the CSNAT intervention}

Implementation required both external facilitation by the research team and internal facilitation by sites, informed by prior pilot and feasibility studies. ${ }^{13} 14$ External facilitation ensured aims and requirements for implementation and the trial were established through documentation and meetings with service managers, lead practitioners and administrators. Training was conducted with all staff involved in the intervention, consisting of two sessions of $2 \mathrm{~h} 1$ week apart. Session 1 covered reflection on current carer assessment, introduction of the CSNAT intervention and how it differed from current practice. Session 2 covered how practitioners could use the intervention during carer contacts and how it would integrate with existing administration, recording and service procedures. A service lead practitioner led the latter component. Each service nominated 1-2 CSNAT Champions to lead the CSNAT implementation. These were supported through regular contacts with the Research Associate (RA), monthly Skype meetings with Champions at other participating sites and two cross-site Champion face-to-face meetings. Research team members met with practitioners involved in the intervention 1-2 months after start of implementation to identify and address any queries. The RA liaised several times per month with core team members to discuss and resolve ongoing issues. A website provided documentation and further means of communication.
Internal facilitation included organisational preparation, formation of a core team (champion, manager, administrator) to steer implementation, adoption of a change management approach and enhancing mutual practitioner support.

\section{Recruitment}

Site administrators identified name and contact details of the main carer or next-of-kin (NOK) of all patients who died during the trial period (representing the total sampling frame). Survey packs were sent to carers 4-5 months postbereavement. Previous research indicates 4-6 months may yield the best response rates, while avoiding the period of most intense grieving, ${ }^{19}$ but hopefully preserving accuracy of recall. Exclusion criteria were carer age $<18$ years or being identified by site practitioners as experiencing particularly complicated grief. Administrators recorded surveys sent and reasons for any exclusions.

Survey packs contained an invitation letter from the service, participant information sheet, consent forms, a questionnaire booklet and freepost envelope. Carers sent completed surveys to the RA.

Data from previous cross-sectional hospice home care research ${ }^{6}$ showed a difference of 8.7 (SD 12.6) in postbereavement SF-36 mental health scores between carers who reported sufficient psychological support during end of life care and those who did not, representing a standardised effect size of 0.69. However, cross-sectional designs may inflate effect size. For the trial, we assumed an effect size of half of this would be more realistic $(0.345)$. The need to reduce survey response burden furthermore led to a switch to the shorter SF-12 mental health scale. Based on Monte-Carlo simulation a stepped wedge trial with six clusters (sites) with five time bands (steps) and on average 18 patients per time band per cluster $(\mathrm{N}=540)$ should have $80 \%$ power to detect a standardised effect of 0.345 assuming an intracluster correlation of 0.05 and a $5 \%$ significance level. Early data from participating sites indicated they had $\mathrm{N}=3600$ deaths over 15 months, making the required carer sample of $\mathrm{N}=540$ feasible even with high exclusion $(0.20)$ and low response rates $(0.25)$. 


\section{Data collection}

Sampling frame information

Site administrators completed monthly spreadsheets from service records for all patient deaths during the trial to compile the study sampling frame. This included study ID number, patient age, gender, diagnosis, date and place of death; and the name and contact details of main carer or NOK, their gender and relationship to the patient to enable identification of carers for the survey. Anonymised information from the sampling frame was provided for analysis. Data could be linked to individual survey respondents with their consent.

Outcome variables

The survey collected information on carers' age, gender and relationship with the patient.

Primary outcome survey measures comprised adequacy of support provided for the carer during end of life care giving and physical and psychological wellbeing in bereavement. Perceived adequacy of support was measured using 14 questions based on the CSNAT domains, using the format 'Did you need more support with-' (responses: 1-no; 2-a little more; 3-quite a bit more; 4-very much more). Scores were summarised for the analysis. A further three questions asked whether carers had been asked about their support needs, felt their needs had been listened to, and whether there were concerns they had been unable to discuss (responses: 1-always, 2-usually, 3 -sometimes, 4-never). Level of grief in bereavement was measured using the Texas Revised Inventory of Grief (TRIG) ${ }^{20}$ which covers early (immediately after death) and current grief. Psychological and physical well-being was measured using the SF-12v2, ${ }^{21}$ and distress using the Distress Thermometer (DT). ${ }^{22}$ General practitioner (GP) contacts postbereavement were collected as a further indicator of physical health.

Secondary outcome survey measures were place of death (home, hospice, hospital, nursing/ residential home, other) and whether the place of death was felt to be the best place (yes, no, mixed feelings, don't know). Information on place of death on all patients was furthermore provided through the sampling frame information on place of death. Place of death was dichotomised into 'home'/'not home'.

Process data on implementation of the intervention

Administrators provided monthly summaries on number of new patients, patients on the caseload and number of CSNAT assessments completed for new patients and total caseload. They also recorded which carers had a CSNAT intervention on the site spreadsheet.

Qualitative information on implementation was collected from practitioners through face-to-face interviews, focus groups and workshops. In addition, field notes were completed of all RA contacts with participating sites to form a 'diary' of activity relating to the implementation. Qualitative findings will be reported in detail elsewhere.

\section{Analysis}

Response modelling

Factors affecting survey response rates were investigated using a logistic mixed-effects model. This included a random effect for site and a fixed effect for time (see below). All available patient and carer data from service records were examined as predictors for survey response. These were: carer gender; the relationship of patient to carer; patient age, and patient diagnosis. The intracluster correlation coefficient was also estimated to assess the strength of response clustering between carers of patients from the same site.

\section{Outcomes}

Analyses to test for differences in outcomes between control and intervention groups were based on intention to treat (ie, included all intervention participants whether they received the CSNAT intervention or not) and were adjusted for site, patient and carer variables. Outcomes were analysed using mixed-effects models to account for the stepped-wedge clusterrandomised trial design, by including a random effect for site and a fixed effect for time. ${ }^{23}$ For quantitative and summary score outcomes, linear mixed effect models were used. To assess the number of carer GP contacts since patients' death, a Poisson mixed-effects model was used; the rate ratio was estimated to evaluate the intervention effect. For questions with ordinal responses, a cumulative logistic mixed-effects model was used, under the proportional odds assumption. For secondary binary outcomes, a logistic mixed-effects model was used. Both logistic and cumulative logistic models provided estimates of the intervention effect via an OR.

All analyses of outcomes included adjustment for carer gender, the relationship of patient to carer (partner/parent/sibling/other), patient age and diagnosis (cancer/other). For variables obtained from both service records and surveys (carer gender, relationship between patient and carer and place of death) unavailable data in service records were imputed from available survey response data and vice-versa. For analyses, any remaining missing categorical covariate values were imputed as a separate 'unknown' category value and missing continuous covariate values were imputed using simple conditional mean imputation. ${ }^{24}$ The statistical significance of intervention effects was inferred from the likelihood ratio test, and 95\% CIs of intervention effect estimates were constructed with normal (Wald) approximations.

\section{RESULTS}

\section{Sample}

There were large differences in sample sizes across sites supporting the appropriateness of incorporating 
clustering by site in all analyses. There were no obvious imbalances of carer/patient characteristics between control and intervention arms (table 3).

One site initially had two separate, but collaborating services included in the trial. However, the smaller service was withdrawn after some months as coordination procedures were not felt to work well enough to fully guarantee that a carer would not be sent the survey twice. This represented removal of 265 deaths from the initial sampling frame.

There were 4311 deaths in the remaining participating services during the trial $(2268$ control, 1478 intervention; table 3). Surveys were sent to carers in 3260 $(76 \%)$ cases. A main recorded reason for not sending a survey was missing or incomplete carer details (439/ $1051 ; 42 \%$; as opposed to 'no carer'). Of surveys sent, $681(21 \%)$ were returned. Forty-eight respondents $(7 \% ; 22$ control, 26 intervention) did not enclose consent to link their survey and service record data, and the data of the latter were imputed for the analysis (see Analysis). Table 2 shows details of patient deaths and surveys sent.

There was a wide range in the unadjusted survey response rates across sites. There was some evidence for difference in response rate by certain predictors. The independent OR estimates (95\% CI) for survey response in (1) the intervention arm compared with control, (2) female carers compared with male carers and (3) carers of patients diagnosed with cancer compared with those with other diseases were $1.30(0.92$ to 1.82 ) and 1.14 (0.93 to 1.40 ) and 1.00 (0.75 to $1.34)$, respectively. There was no statistically significant effect for a difference in response rate across time/phase. Compared with carers who were partners of patients, the OR estimates $(95 \% \mathrm{CI})$ of carers recorded as being (1) parents, (2) siblings or (3) other of patients were 0.92 (0.73 to 1.15$), 0.93$ (0.50 to 1.73 ) and 0.48 (0.27 to 0.85$)$, respectively. Once these predictors were adjusted for, the variation across sites was small; the intraclass correlation coefficient within site was estimated to be 0.017 , indicating a low clustering effect of site on the response rate.

\section{Outcomes}

Table 4 shows observed, unadjusted primary and secondary outcomes by trial arm. Relative to carer survey reports, services slightly over-reported deaths at home, but this effect appeared similar for control and intervention patients. Table 5 shows adjusted estimates of the effect of the intervention on outcomes.

In the intervention group, there was evidence of reduction in early grief (TRIG-1) and improvements

Table 3 Patient and carer characteristics

\begin{tabular}{|c|c|c|c|c|c|c|}
\hline \multicolumn{3}{|c|}{$\begin{array}{l}\text { Characteristics of patients and carers associated with all } \\
\text { deaths at trial sites }\left(n=4311, n_{C}=2268, n_{1}=2043\right)\end{array}$} & \multicolumn{4}{|c|}{$\begin{array}{l}\text { Characteristics of patients and carers in survey response sample } \\
\left(n=681, n_{C}=333, n_{l}=348\right)\end{array}$} \\
\hline & All deaths & Missing & Control & Missing & Intervention & Missing \\
\hline \multicolumn{7}{|l|}{ Carer gender (\%) } \\
\hline Male & $1322(34)$ & $440(12)$ & $101(33)$ & $24(8)$ & $90(29)$ & $35(11)$ \\
\hline Female & $2549(66)$ & & $208(67)$ & & $223(71)$ & \\
\hline \multicolumn{7}{|c|}{ Patient relationship to carer (\%) } \\
\hline Partner & $2248(56)$ & $302(7)$ & $208(67)$ & $22(7)$ & $222(69)$ & $26(8)$ \\
\hline Parent & $1266(32)$ & & $84(27)$ & & $89(28)$ & \\
\hline Sibling & $127(3)$ & & $8(3)$ & & $6(2)$ & \\
\hline Other & $368(9)$ & & $11(4)$ & & $5(2)$ & \\
\hline Mean patient age (SD) & $73.4(-12.1)$ & $55(1)$ & $71.5(-10.6)$ & $24(8)$ & $72.2(-12.2)$ & $26(8)$ \\
\hline \multicolumn{7}{|l|}{ Patient gender (\%) } \\
\hline Male & $2269(53)$ & $48(1)$ & $142(46)$ & $22(7)$ & $147(46)$ & $26(8)$ \\
\hline Female & $1994(47)$ & & $169(54)$ & & $175(54)$ & \\
\hline \multicolumn{7}{|l|}{ Patient diagnosis (\%) } \\
\hline Cancer & $3701(88)$ & $87(2)$ & $271(88)$ & $26(8)$ & $282(88)$ & $28(9)$ \\
\hline Other & $523(12)$ & & $38(12)$ & & $38(12)$ & \\
\hline \multicolumn{7}{|l|}{ Carer gender $(\%)^{*}$} \\
\hline Male & & & $109(33)$ & $5(2)$ & $97(28)$ & $5(2)$ \\
\hline Female & & & $219(67)$ & & $246(72)$ & \\
\hline \multicolumn{7}{|c|}{ Patient relationship to carer (\%)* } \\
\hline Partner & & & $222(67)$ & $1(0)$ & $231(67)$ & $1(0)$ \\
\hline Parent & & & $91(27)$ & & $100(29)$ & \\
\hline Sibling & & & $5(2)$ & & $6(2)$ & \\
\hline Other & & & $14(4)$ & & $10(3)$ & \\
\hline
\end{tabular}

(Note: these summaries are unadjusted for sample sizes at each site and time).

*Data from survey responses, all other data from service records. 
Table 4 Observed outcomes in the survey response sample $\left(n=681, n_{C}=333, n_{1}=348\right)$

\begin{tabular}{|c|c|c|c|c|}
\hline Outcome & Control & Missing (\%) & Intervention & Missing (\%) \\
\hline$\overline{\text { CSNAT total (SD) }}$ & $20.9(-7.6)$ & $17(5)$ & $21(-7.4)$ & $14(4)$ \\
\hline \multicolumn{5}{|l|}{ Asked about support needs (\%) } \\
\hline 'Never' & $31(10)$ & \multirow[t]{5}{*}{$9(3)$} & $25(8)$ & \multirow[t]{5}{*}{$17(5)$} \\
\hline 'Sometimes' & $53(18)$ & & $78(26)$ & \\
\hline 'Usually' & $56(19)$ & & $71(23)$ & \\
\hline 'Always' & $132(44)$ & & $106(35)$ & \\
\hline 'Not applicable' & $30(10)$ & & $25(8)$ & \\
\hline \multicolumn{5}{|l|}{ Listened to (\%) } \\
\hline 'Never' & $12(4)$ & \multirow[t]{5}{*}{$10(3)$} & $14(5)$ & \multirow[t]{5}{*}{$15(5)$} \\
\hline 'Sometimes' & $24(8)$ & & $25(8)$ & \\
\hline 'Usually' & $46(15)$ & & $69(22)$ & \\
\hline 'Always' & $182(60)$ & & $177(57)$ & \\
\hline 'Not applicable' & $37(12)$ & & $22(7)$ & \\
\hline \multicolumn{5}{|l|}{ Unable to discuss concerns (\%) } \\
\hline 'Always' & $3(1)$ & \multirow[t]{5}{*}{$20(6)$} & $2(1)$ & \multirow[t]{5}{*}{$26(8)$} \\
\hline 'Usually' & $8(3)$ & & $8(3)$ & \\
\hline 'Sometimes' & $56(19)$ & & $61(21)$ & \\
\hline 'No never' & $203(70)$ & & $198(67)$ & \\
\hline 'Don't know' & $21(7)$ & & $27(9)$ & \\
\hline TRIG-1 early grief (SD) & $23.3(-8.2)$ & $17(5)$ & $21.7(-7.7)$ & $15(5)$ \\
\hline TRIG-2 present grief (SD) & $49.9(-11.4)$ & $12(4)$ & $48.4(-11.2)$ & $6(2)$ \\
\hline SF-12 mental (SD) & $39.2(-11.8)$ & $5(2)$ & $40.5(-11.3)$ & $7(2)$ \\
\hline SF-12 physical (SD) & $48.5(-11.7)$ & $5(2)$ & $51.1(-10.1)$ & $7(2)$ \\
\hline Distress level (SD) & $4.6(-2.6)$ & $2(1)$ & $4.4(-2.7)$ & $10(3)$ \\
\hline Median number of carer GP visits since death (range) & $1(0,11)$ & $8(3)$ & $1(0,12)$ & $8(2)$ \\
\hline \multicolumn{5}{|l|}{ Place of death was best place (\%) } \\
\hline Yes & $224(73)$ & \multirow[t]{2}{*}{$3(1)$} & $261(82)$ & \multirow[t]{2}{*}{$3(1)$} \\
\hline Other & $84(27)$ & & $58(18)$ & \\
\hline \multicolumn{5}{|l|}{ Place of death at home (survey) (\%) } \\
\hline Yes & $140(45)$ & \multirow[t]{2}{*}{$2(1)$} & $171(53)$ & \multirow[t]{2}{*}{$2(1)$} \\
\hline No & $169(55)$ & & $149(47)$ & \\
\hline \multicolumn{5}{|l|}{ Place of death at home (service-respondents only) (\%) } \\
\hline Yes & $148(48)$ & \multirow[t]{2}{*}{$0(0)$} & $180(56)$ & \multirow[t]{2}{*}{$0(0)$} \\
\hline No & $163(52)$ & & $142(44)$ & \\
\hline \multicolumn{5}{|l|}{ Place of death at home (service-all records) (\%) } \\
\hline Yes & $1040(46)$ & \multirow[t]{2}{*}{$23(1)$} & $1044(52)$ & \multirow[t]{2}{*}{$25(1)$} \\
\hline No & $1206(54)$ & & $973(48)$ & \\
\hline
\end{tabular}

Note: these summaries are unadjusted for sample sizes at each site and time and for other covariates.

CSNAT, Carer Support Needs Assessment Tool; GP, general practitioner; TRIG, Texas Revised Inventory of Grief.

in mental and physical health (SF-12) compared with the control group, although improvements were at most moderate. Most intervention effect estimates on primary outcomes $(7 / 10)$ were in a favourable direction even if not always statistically significant. However, there was no indication that the intervention group felt their needs had been met (CSNAT total), or their support needs probed or listened to, to a greater extent than the control group.

For survey respondents, there was evidence of a favourable intervention effect on probability of death at home and seeing the place of death as the best place, with an OR of approximately 2 for each.
Although survey records for all deaths also indicate a favourable effect on the probability of dying at home, the adjusted analysis did not support this.

\section{Implementation of the intervention}

Monthly summaries of CSNAT assessments were obtained from four of the five sites that began the intervention during the trial, but to varying levels of completeness. Three provided monthly data on number of new patients, and CSNATs handed out and completed for carers of new patients. Two of these services also provided data on total numbers on caseload, and total CSNATs handed out and completed 
Table 5 Estimate of effect of intervention with ICC on site

\begin{tabular}{|c|c|c|c|c|c|}
\hline Outcome & Intervention effect & $95 \% \mathrm{Cl}$ & p Value & Favourable result & ICC \\
\hline \multicolumn{6}{|c|}{$\begin{array}{l}\text { Estimate of effect of intervention on quantitative or summary score outcomes ( }{ }^{*} \text { Rate ratio from Poisson mixed-effects model, all other estimates from linear } \\
\text { mixed-effects models) }\end{array}$} \\
\hline CSNAT total $(n=646)$ & -0.36 & $(-2.17,1.44)$ & 0.684 & $<0$ & 0.108 \\
\hline TRIG-1 early $(n=645)$ & -1.96 & $(-3.83,-0.09)$ & 0.038 & $<0$ & 0.106 \\
\hline TRIG-2 present $(n=659)$ & -1.24 & $(-3.95,1.47)$ & 0.322 & $<0$ & 0.204 \\
\hline SF-12 mental $(n=666)$ & 2.58 & $(0.00,5.15)$ & 0.049 & $>0$ & 0.073 \\
\hline SF-12 physical $(n=666)$ & 3.09 & $(0.64,5.53)$ & 0.011 & $>0$ & 0.105 \\
\hline Distress level $(n=665)$ & -0.18 & $(-0.79,0.44)$ & 0.508 & $<0$ & 0.029 \\
\hline Number of GP visits since patient death $(n=662)$ & $1.02^{*}$ & $(0.86,1.20)$ & 0.833 & $<1$ & 0.000 \\
\hline \multicolumn{6}{|c|}{ Estimate of effect of intervention (proportional OR) on ordinal response outcomes (ICC calculated on latent scale) } \\
\hline Asked about support needs $(n=595)$ & 0.77 & $(0.47,1.26)$ & 0.38 & $>1$ & 0.013 \\
\hline Listened to $(n=591)$ & 0.87 & $(0.51,1.46)$ & 0.600 & $>1$ & 0.016 \\
\hline Unable to discuss concerns $(n=577)$ & 1.05 & $(0.55,2.00)$ & 0.890 & $>1$ & 0.026 \\
\hline \multicolumn{6}{|c|}{ Estimate of effect of intervention (OR) on secondary binary outcomes (ICC calculated on latent scale) } \\
\hline Place of death was best place $(n=673)$ & 1.94 & $(1.06,3.56)$ & 0.033 & $>1$ & 0.032 \\
\hline Place of death at home (survey), $(n=675)$ & 2.13 & $(1.25,3.61)$ & 0.006 & $>1$ & 0.036 \\
\hline Place of death at home (service), $(n=4263) \ddagger$ & 0.957 & $(0.76,1.20)$ & 0.698 & $>1$ & 0.029 \\
\hline
\end{tabular}

$¥$ Model fitted to all carer/patient records, not just survey respondents.

CSNAT, Carer Support Needs Assessment Tool; GP, general practitioner; ICC, intracluster correlation; TRIG, Texas Revised Inventory of Grief.

for total caseload. One provided information on CSNATs handed out and completed, but not on the denominators.

Based on available summary data, 985 CSNATs were reported to have been handed out to carers, but CSNAT assessments were completed in only 209 $(21.2 \%)$ of these cases (range of completion across sites: $13.7-56.3 \%)$. CSNATs were reportedly handed out to $685(41.6 \%)$ carers of 1645 new patients, and completed for 113 of these (completion rate 16.5\%). Where total caseload numbers are available, CSNATs was handed out to 789 (32.1\%) of 2461 on total caseload (completion rate 20.0\%).

\section{DISCUSSION}

Results show that compared with the control group the intervention group had small but significant reductions in levels of early grief and improvements in psychological and physical health.

Correspondingly, results from Australia indicate that CSNAT use may benefit carers and reduce carer strain. ${ }^{25}{ }^{26}$ Furthermore, among our survey respondents, the intervention carers were significantly more likely to feel the place of death was right and patients more likely to die at home. However, the latter result was not significant when considering service records for all deaths (respondents, non-respondents and those not surveyed). This may reflect underlying differences between survey respondents and non-respondents, the latter being a much larger group. Although not evident by table 3 , there may be differences in unrecorded characteristics that, for example, may make home death both more likely and more responsive to the intervention condition in the survey group.
Overall, there appears to be favourable effects of the intervention, but differences were small, and intervention carers were not more likely to feel their needs had been met. However, the process data indicate that implementation of the CSNAT intervention was limited, both in terms of numbers of carers affected and the extent to which the intervention was delivered as intended. Available data indicate that the CSNAT was only handed out to carers of a third of patients in total. Furthermore, while a reasonable proportion of carers may have seen the CSNAT, potentially alongside other paperwork, CSNAT assessment was only completed in a minority of cases. Completion in itself may not mean there was subsequent discussion about carers' needs, priorities and preferred solutions and follow-up action plans. This low level of implementation means the CSNAT intervention would have limited opportunity to make a strong direct impact.

Improvements in the intervention group may therefore in part result from awareness raising regarding carers' needs through activities surrounding the implementation of the intervention, including training, champions' efforts, regular RA contacts, keeping CSNAT on staff meeting agendas and encouragement by managers. However, if significant improvements, albeit small, may be produced by low level implementation and general awareness raising, it is plausible that more substantial improvements can be achieved if the CSNAT intervention can be delivered to the majority of carers in its intended form, that is, an assessment and support process based on carers' selfidentified needs, priorities and solutions.

While there was no doubt about efforts expended by sites participating in the trial, implementation of 
the CSNAT intervention presented greater challenges than expected. Qualitative data collection helped identify main factors that affected implementation, illustrating the value of a mixed-methods approach to trials. ${ }^{27}$ While these factors will be reported in detail elsewhere, in brief outline they encompassed practitioner perceptions and engagement, service context factors, external and internal facilitation: the CSNAT intervention represented a step change in practice, but practitioners may not perceive its value over existing practice and/or have concerns over workload impact. Services differed in the extent to which existing administrative systems and working practices enabled the CSNAT intervention to be easily integrated and carers to be accommodated as clients in their own right. This included existing opportunities for carer identification, contact and recording of support needs and actions. Internal facilitation was affected by time and availability of management leads, champions' opportunities for leverage and organisational resources to support implementation in the face of competing demands and staffing levels. External facilitation did not fully address the step change that the intervention represented. Our findings correspond with the components of the Promoting Action on Research Implementation in Health Services (PARIHS) framework for implementation where implementation of a complex intervention depends on the perceived value of the intervention, service context and facilitation. ${ }^{28} 29$

The research was also affected by some of the service factors. Missing information on main carers or NOK increased administrator workloads in chasing information, reduced numbers of surveys sent and left less time for supplying process data. Lack of procedures for routine recording of CSNAT assessments and follow-up actions also hampered further collection and analysis of process information. Service support costs for recruitment were fully covered, but this was only helpful if services could appoint additional staff. Services' ability to fit in a practice change at the time furthermore meant that (constrained) randomisation only occurred in four of six participating sites; therefore, some selection biases and imbalances between the control and intervention samples are possible.

\section{CONCLUSION}

The trial highlights the importance of investing effort in understanding implementation of complex interventions as recommended by the MORECare guidance for palliative care ${ }^{30}$ and the MRC Framework for evaluations. ${ }^{31}$ Our trial furthermore illustrates the value of mixed methods and process measures to understand how complex interventions behave in a practice context. ${ }^{27} 31$

Furthermore, the trial highlights the challenges in implementing comprehensive carer assessment and support: our qualitative data indicate that carers are not 'visible' on administrative systems in that often carer details are not recorded and there are commonly no consistent means of documenting their needs as separate from patients; that practice procedures often do not afford opportunity for regular carer contact, assessment and follow-up; and that engagement with assessment of carers' needs separately from the patient and with carer-led assessment represents a significant step change for practitioners. These challenges need to be recognised and addressed before guidelines and government recommendations that carer needs should be assessed and addressed ${ }^{9}{ }^{10}$ can have meaningful impact. We have used trial findings to develop a training and implementation package to improve external facilitation and encourage better internal facilitation of the CSNAT intervention and are testing this in an implementation study with improved results.

Acknowledgements The authors wish to thank all the practitioners, managers and administrators at our study sites and all the carer participants involved in the study.

The survey used the question wording, answer categories and order of questions identical to SF-12v2, but their appearance was changed to make a more user-friendly bereavement survey booklet. They were therefore not in a format approved by OptumInsight Life Sciences (QualityMetric), and due to these modifications, scores may not necessarily be reliable or valid.

Disclaimer The views expressed are those of the authors and not necessarily those of the NHS, the NIHR or the Department of Health.

Funding NIHR Research for Patient Benefit Programme (Grant Reference Number PB-PG-0610-22291).

Competing interests None declared.

Ethics approval NRES Committee North West-Greater Manchester East (12/NW/0206).

Provenance and peer review Not commissioned; externally peer reviewed.

Open Access This is an Open Access article distributed in accordance with the Creative Commons Attribution Non Commercial (CC BY-NC 4.0) license, which permits others to distribute, remix, adapt, build upon this work noncommercially, and license their derivative works on different terms, provided the original work is properly cited and the use is non-commercial. See: http://creativecommons.org/licenses/by$\mathrm{nc} / 4.0 /$

\section{REFERENCES}

1 Gomes B, Higginson IJ. Factors influencing death at home in terminally ill patients with cancer: systematic review. $B M J$ 2006;332:515-21.

2 Grande GE, Ewing G. Death at home unlikely if informal carers prefer otherwise: implications for policy. Palliat Med 2008;22:971-2.

3 Aoun SM, Kristjanson LJ, Currow DC, et al. Caregiving for the terminally ill: at what cost? Palliat Med 2005;19:551-5.

4 Schulz R, Beach SR. Caregiving as a risk factor for mortality. The caregiver health effects study. JAMA 1999;282:2215-19.

5 Grande GE, Farquhar MC, Barclay SI, et al. Caregiver bereavement outcome: relationship with hospice at home, satisfaction with care, and home death. J Palliat Care 2004;20:69-77.

6 Grande GE, Ewing G, National Forum for Hospice at Home. Informal carer bereavement outcome: relation to quality of end of life support and achievement of preferred place of death. Palliat Med 2009;23:248-56. 
7 Rossi Ferrario S, Cardillo V, Vicario F, et al. Advanced cancer at home: caregiving and bereavement. Palliat Med 2004;18:129-36.

8 Park SM, Kim YJ, Kim S, et al. Impact of caregivers' unmet needs for supportive care on quality of terminal cancer care delivered and caregiver's workforce performance. Support Care Cancer 2010;18:699-706.

9 National Institute for Clinical Excellence (NICE). Guidance on cancer services improving supportive and palliative care for adults with cancer. Oxford: NICE, 2004.

10 Department of Health. End of Life Care Strategy: promoting high quality care for all adults at the end of life. Crown copyright. 2008. http://www.dh.gov.uk/en/ Publicationsandstatistics/Publications/ PublicationsPolicyAndGuidance/DH_086277

11 Ewing G, Grande GE. Development of a Carer Support Needs Assessment Tool (CSNAT) for end of life care practice at home: a qualitative study. Palliat Med 2013;27:244-56.

12 Ewing G, Brundle C, Payne S, et al. The Carer Support Needs Assessment Tool (CSNAT) for use in palliative and end of life care at home: a validation study. J Pain Symptom Manage 2013;46:395-405.

13 Ewing G, Austin L, Grande G. The role of the Carer Support Needs Assessment Tool in palliative home care: a qualitative study of practitioners' perspectives of its impact and mechanisms of action. Palliative medicine Published Online First: 2015. Doi: 10.1177/0269216315596662.

14 Ewing G, Austin L, Grande G. Using the Carer Support Needs Assessment Tool (CSNAT) in practice: What have we learned? Palliat Med Abstracts of the 7th World Research Congress of the European Association for Palliative Care (EAPC) 2012;26:630-1.

15 Mdege ND, Man MS, Taylor CA, et al. Systematic review of stepped wedge cluster randomized trials shows that design is particularly used to evaluate interventions during routine implementation. J Clin Epidemiol 2011;64:936-48.

16 Craig N, Dieppe P, Macintyre S, et al. Developing and evaluating complex interventions: new guidance. Med Res Counc 2008. http://www.mrc.ac.uk/complexinterventions guidance (last accessed 16th November 2015)

17 Brown CA, Lilford RJ. The stepped wedge trial design: a systematic review. BMC Med Res Methodol 2006;6:54.

18 Brown C, Lilford R. Evaluating service delivery interventions to enhance patient safety. BMJ 2009;338:159-63.

19 Gomes B, McCrone P, Hall S, et al. Variations in the quality and costs of end-of-life care, preferences and palliative outcomes for cancer patients by place of death: the QUALYCARE study. BMC Cancer 2010;10:400.

20 Faschingbauer TR, Zisook S, DeVaul R. (1987). The Texas revised inventory of grief. In: Zisook S, ed. Biopsychosocial aspects of bereavement. Washington DC: American Psychiatric Press Inc., 2007:108-24.

21 Jenkinson C, Layte R. Development and testing of the UK SF-12 (short form health survey). J Health Serv Res Policy 1997;2:14-18.

22 Zwahlen D, Hagenbuch N, Carley MI, et al. Screening cancer patients' families with the distress thermometer (DT): a validation study. Psychooncology 2008;17:959-66.

23 Hussey MA, Hughes JP. Design and analysis of stepped wedge cluster randomized trials. Contemp Clin Trials 2007;28:182-91.

24 White IR, Thompson SG. Adjusting for partially missing baseline measurements in randomized trials. Stat Med 2005;24:993-1007.

25 Aoun S, Deas K, Toye C, et al. Supporting family caregivers to identify their own needs in end-of-life care: qualitative findings from a stepped wedge cluster trial. Palliat Med 2015;29:508-17.

26 Aoun SM, Grande G, Howting D, et al. The impact of the Carer Support Needs Assessment Tool (CSNAT) in community palliative care using a stepped wedge cluster trial. PLOS ONE 2015;10:e0123012.

27 Farquhar M, Preston N, Evans CJ, et al. MORECare. Mixed methods research in the development and evaluation of complex interventions in palliative and end of life care: report on the MORECare consensus exercise. J Palliat Med 2013;16:1550-60.

28 Rycroft-Malone J, Harvey G, Seers K, et al. An exploration of the factors that influence the implementation of evidence into practice. J Clin Nurs 2004;13:913-24.

29 Kitson AL, Rycroft-Malone J, Harvey G, et al. Evaluating the successful implementation of evidence into practice using the PARiHS framework: theoretical and practical challenges. Implement Sci 2008;3:1.

30 Higginson IJ, Evans CJ, Grande G, et al. Evaluating complex interventions in End of Life Care: the MORECare Statement on good practice generated by a synthesis of transparent expert consultations and systematic reviews. BMC Med 2013;11:111.

31 Moore GF, Audrey S, Barker M, et al. Process evaluation of complex interventions: Medical Research Council guidance. BMJ 2015;350:h1258. 